\title{
Application of open-path Fourier transform infrared spectroscopy (OP-FTIR) to measure greenhouse gas concentrations from agricultural fields
}

\author{
Cheng-Hsien Lin ${ }^{1}$, Richard H. Grant ${ }^{1}$, Albert J. Heber ${ }^{2}$, and Cliff T. Johnston ${ }^{1,3}$ \\ ${ }^{1}$ Department of Agronomy, Purdue University, West Lafayette, IN 47907, USA \\ ${ }^{2}$ Department of Agricultural and Biological Engineering, Purdue University, West Lafayette, IN 47907, USA \\ ${ }^{3}$ Department of Earth, Atmospheric and Planetary Sciences, Purdue University, West Lafayette, IN 47907, USA
}

Correspondence: Cheng-Hsien Lin (lin471@ @urdue.edu)

Received: 24 October 2018 - Discussion started: 7 December 2018

Revised: 25 May 2019 - Accepted: 29 May 2019 - Published: 27 June 2019

\begin{abstract}
Open-path Fourier transform infrared spectroscopy (OP-FTIR) has often been used to measure hazardous or trace gases from hot point sources (e.g. volcano, industrial, or agricultural facilities) but seldom used to measure greenhouse gases (GHGs) from field-scale sources (e.g. agricultural soils). Closed-path mid-IR laser-based $\mathrm{N}_{2} \mathrm{O}$, nondispersive-IR $\mathrm{CO}_{2}$ analysers, and OP-FTIR were used to measure concentrations of $\mathrm{N}_{2} \mathrm{O}$ and $\mathrm{CO}_{2}$ at a maize cropping system during 9-19 June 2014. To measure $\mathrm{N}_{2} \mathrm{O}$ and $\mathrm{CO}_{2}$ concentrations accurately, we developed a quantitative method of $\mathrm{N}_{2} \mathrm{O} / \mathrm{CO}_{2}$ analysis that minimized interferences from diurnal changes of humidity and temperature. Two chemometric multivariate models, classical least squares (CLS) and partial least squares (PLS), were developed. This study evaluated various methods to generate the single-beam background spectra and different spectral regions for determining $\mathrm{N}_{2} \mathrm{O}$ and $\mathrm{CO}_{2}$ concentrations from OP-FTIR spectra. A standard extractive method was used to measure the actual path-averaged concentrations along an OP-FTIR optical path in situ, as a benchmark to assess the feasibilities of these quantitative methods. Within an absolute humidity range of 5000-20 000 ppmv and a temperature range of $10-35^{\circ} \mathrm{C}$, we found that the CLS model underestimated $\mathrm{N}_{2} \mathrm{O}$ concentrations (bias $=-4.9 \pm 3.1 \%$ ) calculated from OP-FTIR spectra, and the PLS model improved the accuracy of calculated $\mathrm{N}_{2} \mathrm{O}$ concentrations (bias $=1.4 \pm 2.3 \%$ ). The bias of calculated $\mathrm{CO}_{2}$ concentrations was $-1.0 \pm 2.8 \%$ using the CLS model. These methods suggested that environmental variables potentially lead to biases in $\mathrm{N}_{2} \mathrm{O}$ and $\mathrm{CO}_{2}$ estimations
\end{abstract}

from OP-FTIR spectra and may help OP-FTIR users avoid dependency on extractive methods of calibrations.

\section{Introduction}

Agriculture contributes a substantial amount of greenhouse gas (GHG) emissions (e.g. $\mathrm{N}_{2} \mathrm{O}, \mathrm{CO}_{2}$, and $\mathrm{CH}_{4}$ ) to the global GHG budget (IPCC, 2007; Cole et al., 1997; Smith et al., 2008). Among these gases, $\mathrm{N}_{2} \mathrm{O}$ is mainly emitted from agricultural soils, accounting for $38 \%$ of the global anthropogenic non- $\mathrm{CO}_{2}$ GHG emissions from agricultural activities (US-EPA, 2006; Smith et al., 2007). Nitrous oxide is produced from biological reactions that transform available $\mathrm{N}$ in soils via microbial nitrification and denitrification (Mosier et al., 2004). Considering that the global warming potential value of $\mathrm{N}_{2} \mathrm{O}$ is 310 , it is estimated that overall GHG emission from soils (based on $\mathrm{CO}_{2}$ equivalents) is approximately $2500 \mathrm{Mt}$ of $\mathrm{CO}_{2}$ equivalent per year. A significant fraction of soil $\mathrm{N}_{2} \mathrm{O}$ emissions results from the use of nitrogen $(\mathrm{N})$ fertilizers in agricultural soils. In addition to contributing to the overall GHG burden of the atmosphere, $\mathrm{N}_{2} \mathrm{O}$ emissions also represent a direct loss of $\mathrm{N}$ applied to the field, contributing to the decreased nitrogen use efficiency (NUE) (Eichner, 1990; Ryden and Lund, 1980; Bremner et al., 1981; Omonode et al., 2017). Also, soils play the role of a sink or a source for atmospheric $\mathrm{CO}_{2}$ (Paustian et al., 1997; Smith et al., 2008). Changing land use of crop production, especially agriculture-related uses such as tile drainage and tillage man- 
agement, and agricultural lime application (e,g., $\mathrm{CaCO}_{3}$ and $\left.\mathrm{MgCa}\left(\mathrm{CO}_{3}\right)_{2}\right)$ potentially become a large source of $\mathrm{CO}_{2}$ released to the atmosphere via microbial decomposition of soil organic carbon (Smith, 2004; IPCC, 2007; Cole et al., 1997; West et al., 2005).

The flux chamber measurement has been the most common method to measure GHG emissions from soils (Denmead, 2008; Rochette and Eriksen-Hamel, 2008). Chamber measurements, however, are subject to significant limitations that lead to uncertainties and biases in estimated GHG emissions. For instance, because chambers have a small footprint $\left(\sim 0.5 \mathrm{~m}^{2}\right)$ and generally wide sampling intervals (usually once to twice a week), they are poorly suited for evaluating spatial and temporal variabilities of GHGs from agricultural soils (Laville et al., 1999; Rowlings et al., 2012; Schelde et al., 2012). Also, wind turbulence is known to substantially induce more gas transportation from soils to the atmosphere. Chamber methods do not take this wind-induced effect into account, and this likely results in underestimations of gas emissions (Denmead and Reicosky, 2003; Poulsen et al., 2017; Pourbakhtiar et al., 2017). It is worth mentioning that the eddy covariance flux measurement method, one of the most common micro-meteorological techniques used to investigate gas exchanges in the agroecosystem, is capable of measuring gas fluxes frequently with an increased footprint (Baldocchi, 2003). A large-scale flux measurement (hundred metres to several kilometres) using this method, however, makes comparisons among field-scale treatments (1-5 ha) more difficult than chamber methods (Schmid, 1994; Denmead, 2008).

Open-path Fourier transform infrared spectroscopy (OPFTIR) is a non-intrusive sensing approach and capable of detecting multiple components simultaneously, acquiring realtime data at a relatively high temporal resolution (seconds to minutes) and providing path-averaged gas concentrations (Russwurm and Childers, 1996). OP-FTIR has been applied to measuring atmospheric gases since the 1970s (e.g. hazardous air pollutants; fugitive volatile organic compounds, VOCs; and trace gases) (Herget and Brasher, 1980; Gosz et al., 1988; Russwurm et al., 1991; Bacsik et al., 2006; Briz et al., 2007; Lin et al., 2008). More recently, OP-FTIR has been increasingly used to measure GHGs or other trace gases in agriculture, mostly in animal facilities (e.g. $\mathrm{N}_{2} \mathrm{O}, \mathrm{CO}_{2}$, $\mathrm{CH}_{4}$, and $\mathrm{NH}_{3}$ from swine or dairy production) (Childers et al., 2001a; Loh et al., 2008; Bjorneberg et al., 2009; Barrancos et al., 2013; Naylor et al., 2016). Only a few studies, however, implemented OP-FTIR to measure gas emissions from vegetable production fields or fertilized soils (Bai et al., 2014, 2018; Ni et al., 2015). Integrating OP-FTIR with micrometeorological techniques (e.g. flux gradient or backward Lagrangian stochastic dispersion methods) can measure gas fluxes from the field-scale source of interest with high temporal and spatial representations that are less prone to artefacts induced by point-based sampling (Flesch et al., 2004, 2016; Bai et al., 2014, 2018; Ni et al., 2015). Moreover, the OP-
FTIR combined with a scanning system can potentially be applied to horizontally or vertically survey numerous fields of interest and measure their gas emissions simultaneously (Flesch et al., 2016).

Despite these advantages, OP-FTIR also faces a number of challenges. In order to resolve the spectral features of GHGs, high spectral resolution $\left(<0.5 \mathrm{~cm}^{-1}\right)$ is required to resolve the rotation-vibrational absorption bands of the GHGs of interest (Griffiths and de Haseth, 2007). Calculating concentrations from FTIR spectra requires both a sample single-beam spectrum and a reference/background spectrum that does not contain spectral contributions from GHGs of interest, which is not possible at the field scale (e.g. evacuation of the field); thus, mathematical methods have been developed which strip the spectral bands from a sample single-beam spectrum. This challenge requires the use of instrumental- or spectralprocessing methods to create a background spectrum, and these methods are subject to biases in determining GHG concentrations (Griffiths and de Haseth, 2007; Russwurm and Childers, 1996). Furthermore, the atmosphere contains a high concentration of water vapour that interferes with the detection and quantification of GHGs of interest (Russwurm and Childers, 1996; Horrocks et al., 2001; Briz et al., 2007; Smith et al., 2011). These challenges of data processing and the interferences from water vapour likely introduce biases and uncertainties in GHG quantification. Using error-prone concentrations in flux prediction models (micrometeorological techniques) possibly leads to unknown uncertainties in estimated gas fluxes. Thus, it is essential to develop a comprehensive quantitative method to improve and assure the quality of gas quantification using OP-FTIR.

Testing the feasibility of quantitative methods and qualities (accuracy and precision) of OP-FTIR is challenging because a reliable reference is required to validate FTIRderived concentrations. One of the most common approaches was to position a gas cell filled with known gas concentrations of interest in the optical path and test gas quantitative methods (Russwurm et al., 1991; Horrocks et al., 2001; Smith et al., 2011). This approach, however, somewhat controlled the environment and neglected the effect of ambient interferences, such as water vapour, on the quality of gas quantification. The alternative approach is to compare the derived concentrations with ambient concentrations. The ambient concentration of a gas of interest can be determined by averaging the global background concentrations (e.g. $\mathrm{N}_{2} \mathrm{O} \sim 310 \mathrm{ppbv}$ or $\mathrm{CO}_{2} \sim 400 \mathrm{ppmv}$ ) or measured from the gas samples that were collected along the OP-FTIR path and analysing their concentrations using laboratory-based gas chromatography (GC) (ASTM, 2013; Childers et al., 1995; Kelliher et al., 2002; Bai et al., 2014). The experimental designs of these assessment approaches, either the point sampling setup or low sampling frequency or both, became the major problem for cross validating their OP-FTIR quantitative methods. Since the ambient concentrations likely fluctuate from place to place (e.g. different land uses) and at differ- 
ent times (e.g. diurnal or seasonal variation), the spatial and temporal variations of the ambient concentration were potentially misconceived as bias in gas quantification. Up to now, only three studies continuously measured real-time ambient concentration to logically cross validate quantitative methods and data qualities under fluctuating environmental factors (e.g. the dynamic water vapour), but none of the prior studies actually assessed their methodologies for quantifying $\mathrm{N}_{2} \mathrm{O}$ concentrations (Briz et al., 2007; Reiche et al., 2014; Frey et al., 2015).

Therefore, the objectives of this study were to (1) develop a long-path gas sampling system that can continuously collect numerous gas samples simultaneously along an optical path of OP-FTIR and measure path-averaged concentrations to evaluate quantitative qualities of $\mathrm{N}_{2} \mathrm{O}$ and $\mathrm{CO}_{2}$ concentrations derived from OP-FTIR spectra; and (2) optimize the quantitative method, including post-data processing, analytical window selections, and chemometric multivariate algorithms, that is less sensitive to interferences of ambient humidity and temperature and capable of determining $\mathrm{N}_{2} \mathrm{O}$ and $\mathrm{CO}_{2}$ concentrations accurately.

\section{Materials and experimental methods}

\subsection{Site description}

This study was conducted at the Purdue University Agronomy Center for Research and Education near West Lafayette, Indiana, in the United States $\left(86^{\circ} 56^{\prime} \mathrm{W}, 40^{\circ} 49^{\prime} \mathrm{N}\right.$; elevation $215 \mathrm{~m})$. The experimental site was located between two fields $(\sim 3.5$ ha per field) with a continuous corn system since 2013. Gas measurements began just after an anhydrous ammonia application with total $\mathrm{N}$ rate of $220 \mathrm{~kg} \mathrm{NH}_{3}-\mathrm{N} \mathrm{ha}^{-1}$ on 9 June and ended on 19 June 2014. The soils were classified as Drummer silty clay loam (fine-silty, mixed, mesic Typic Endoaquoll) with a bulk density of $1.6 \mathrm{~g} \mathrm{~m}^{-3}$, organic matter of $3.4 \%$, soil $\mathrm{pH}$ of 6.0 , and cation exchange capacity of $23 \mathrm{cmol}_{\mathrm{c}} \mathrm{kg}^{-1}(0-20 \mathrm{~cm})$. During 9-19 June, the cumulative precipitation was $57 \mathrm{~mm}$, and the average soil temperature and moisture from the depth of $0-10 \mathrm{~cm}$ were $23 \pm 3^{\circ} \mathrm{C}$ and $0.32 \pm 0.06 \mathrm{~cm}^{3} \mathrm{~cm}^{-3}$, respectively, which were determined by the on-site weather station.

\subsection{Instrumentation setup}

The spectrometer was a monostatic open-path FTIR air monitoring system (model 2501-C, MIDAC Corporation, Irvine, CA). This instrument included the IR source, interferometer, transmitting/receiving telescope, mercury cadmium telluride (MCT) detector, and ZnSe optics. A mid-IR beam in the spectrometer passed through the atmosphere along an optical path and returned to the telescope after reflection from a retroreflector to collect spectra that included information about the gas of interest. A cube-corner retroreflector with 26 cubes was mounted on a retractable tripod with $150 \mathrm{~m}$ physical path length from the telescope, corresponding to an optical path length of $300 \mathrm{~m}$ (Fig. 1).

Ambient concentrations of $\mathrm{N}_{2} \mathrm{O}$ and $\mathrm{CO}_{2}$ were also determined independently to assess the bias and precision. A difference frequency generation (DFG) mid-IR laser-based $\mathrm{N}_{2} \mathrm{O}$ gas analyser (IRIS 4600, Thermo Fisher Scientific Inc., Waltham, MA) and the non-dispersive infrared (NDIR) spectrometer $\mathrm{CO}_{2}$ gas analyser (LI-840, LI-COR Inc., Lincoln, $\mathrm{NE}$ ) were used to measure $\mathrm{N}_{2} \mathrm{O}$ and $\mathrm{CO}_{2}$ concentrations of the sampled gases from a synthetic open-path gas sampling system (S-OPS) (Fig. 1). The DFG laser-based $\mathrm{N}_{2} \mathrm{O}$ analyser determined $\mathrm{N}_{2} \mathrm{O}$ concentrations in the mid-infrared wavelength with a high precision of $<0.15 \mathrm{ppbv}(1 \sigma, 3 \mathrm{~min}$ averaging). An NDIR $\mathrm{CO}_{2}$ analyser exhibited high accuracy $(<1.5 \%$ of reading) and low noise $(<1.0 \mathrm{ppmv})$ to determine $\mathrm{CO}_{2}$ concentrations using a single-path, dual-wavelength, and infrared detection system.

A $50 \mathrm{~m}$ long S-OPS combined with a gas sampling system (GSS) was used to collect gas samples along an optical path of OP-FTIR. An S-OPS consisted of $9.5 \mathrm{~mm}$ diameter Teflon ${ }^{\circledR}$ tubes and 10 inlets fitted with $1.0 \mu \mathrm{m}$ Teflon ${ }^{\circledR}$ filters. The inlet flow rates were adjusted by critical orifices to $0.70 \mathrm{~L} \mathrm{~min}^{-1}( \pm 10 \%)$. Gas samples were drawn through an S-OPS line by a sampling pump in the GSS at approximately $7 \mathrm{~L} \mathrm{~min}^{-1}$ and collected into a Teflon ${ }^{\circledR}$ ambient pressure chamber. Then, $\mathrm{N}_{2} \mathrm{O}$ and $\mathrm{CO}_{2}$ analysers drew air samples from the ambient pressure chamber to measure the actual path-averaged concentrations of $\mathrm{N}_{2} \mathrm{O}$ and $\mathrm{CO}_{2}$ along the OP-FTIR path (Heber et al., 2006). The measured $\mathrm{N}_{2} \mathrm{O}$ and $\mathrm{CO}_{2}$ concentrations were used to benchmark concentrations calculated from the OP-FTIR spectrum. Temperature, relative humidity, and pressure in the ambient pressure chamber were also recorded every $30 \mathrm{~s}$ to monitor the performance of the GSS.

Meteorological measurements of air temperature and relative humidity were measured using an HMP45C probe (Vaisala Oyj, Helsinki, Finland) at $1.5 \mathrm{~m}$ above ground level (ma.g.l.). The meteorological data were collected by a data logger (model CR1000, Campbell Scientific, Logan, Utah) and averaged every $30 \mathrm{~min}$. Wind speed and direction were acquired from a 3-D sonic anemometer (model 81000, RM Young Inc., Traverse City, MI) mounted at $2.5 \mathrm{~m}$ height on the meteorological mast and recorded at $16 \mathrm{~Hz}$. The recorded data were telemetered to the on-site instrumentation trailer.

\subsection{Overview of ambient temperature, water vapour content, and concentrations of $\mathrm{N}_{2} \mathrm{O}$ and $\mathrm{CO}_{2}$}

The 30 min averages of ambient $\mathrm{N}_{2} \mathrm{O}$ and $\mathrm{CO}_{2}$ concentrations were determined by the S-OPS, and water vapour content and air temperature were measured at the meteorological station (Fig. 2). During the test, 793 valid OP-FTIR spectra with known concentrations of $\mathrm{N}_{2} \mathrm{O}, \mathrm{CO}_{2}$, water vapour, and air temperature were collected. A total of 90 spectra containing $338 \pm 0.3$ ppbv $\mathrm{N}_{2} \mathrm{O}$ and 93 spectra containing 


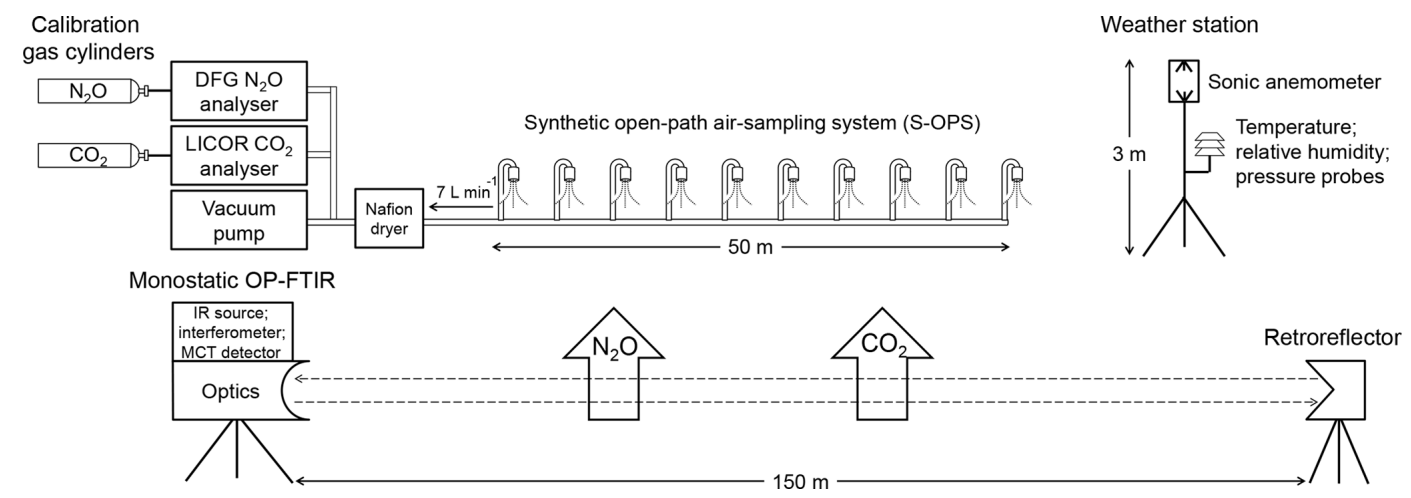

Figure 1. Schematic of the instrumentation used to assess the accuracy of $\mathrm{N}_{2} \mathrm{O}$ and $\mathrm{CO}_{2}$ concentration determined by OP-FTIR in this study. DFG $\mathrm{N}_{2} \mathrm{O}$ and LI-840 $\mathrm{CO}_{2}$ analysers combined with the synthetic open-path air-sampling system (S-OPS) were used to measure the actual path-averaged $\mathrm{N}_{2} \mathrm{O} / \mathrm{CO}_{2}$ concentrations and benchmark the $\mathrm{N}_{2} \mathrm{O}$ and $\mathrm{CO}_{2}$ concentrations calculated from OP-FTIR spectral analyses. The humidity, air temperature, and wind information were measured from the weather station.

$400 \pm 3.0$ ppmv $\mathrm{CO}_{2}$ were selected from these valid spectra to calculate concentrations of $\mathrm{N}_{2} \mathrm{O}$ and $\mathrm{CO}_{2}$, respectively, using different quantitative methods. These groups of spectra with consistent $\mathrm{N}_{2} \mathrm{O} / \mathrm{CO}_{2}$ concentrations but covered by broad ranges of water vapour content and air temperature were used to examine the effect of water vapour and temperature on concentration calculations.

\subsection{OP-FTIR data acquisition and QA/QC procedure}

A spectra range of $500.0-4000.0 \mathrm{~cm}^{-1}$ and a resolution of $0.5 \mathrm{~cm}^{-1}$ were selected for spectra acquisition. Each sampled spectrum was acquired by co-adding 64 single-sided interferograms (IFGs) using the AutoQuant Pro4.0 software package (MIDAC Corporation, Irvine, CA). The IFGs were converted to single-beam (SB) spectra using a zero-filling factor of 1 , triangular apodization, and Mertz phase correction. A straylight SB spectrum was also acquired by daily pointing the transmitting/receiving telescope away from the retroreflector at the beginning of the experiment using the same parameters (Russwurm and Childers, 1996). Each sampled SB spectrum was stray-light corrected by subtracting the stray-light SB spectrum from the sampled SB spectrum before converting to the absorbance spectrum.

The IFGs and corresponding SB spectra were influenced by ambient factors that included wind-derived vibrations, scintillation induced by air mixing, water vapour content, dust accumulation, and condensation on the retroreflector. Criteria of quality assurance were based on the inspection of the IFG and SB spectra, following the standard guideline in the MIDAC instrumentation manual and the FTIR open-path monitoring guidance documents (Russwurm and Childers, 1996) with the supplement criteria published by Childers et al. (2001b) and Shao et al. (2007) to acquire high-quality spectra. The maximum and minimum of the IFG centre bursts were controlled between approximately 0.61 and $1.14 \mathrm{~V}$ of the analogue-to-digital converter based on the physical path length of $150 \mathrm{~m}$. Any IFG centre-burst signals $>2.25 \mathrm{~V}$ were rejected to avoid a non-linear response of the MCT detector.

\subsection{Spectral analyses}

\subsubsection{An absorbance spectrum converted from a single-beam (SB) spectrum}

To calculate a concentration for a given solute, a stray-light corrected SB spectrum is ratioed against an SB background spectrum (GHG-free) to produce an absorbance spectrum from which the gas concentration is determined using the Beer-Lambert law. As discussed earlier, OP-FTIR measurements do not permit the collection of a background spectrum that is free of GHGs. Two different approaches were used in this study to overcome this constraint. Both methods required a normal SB spectrum corresponding to the path length of interest that was then mathematically manipulated to produce a background spectrum. A representative field SB spectrum and the regions of interest for each GHG are shown in Fig. 3a. For the zapped background method, a background (zap-bkg) was obtained by drawing a straight line between two selected points which removed, or "zapped", any spectral contributions below the line using OMNIC Macro Basic 8.0 commercial software (Thermo Fisher Scientific, Inc.). This is illustrated for the $\mathrm{N}_{2} \mathrm{O}$ region of interest in Fig. 3b, with the two points and the line labelled as zapped background. For the zap-bkg method, one quality SB spectrum was selected to create a zap-bkg each day, and all of the sampled SB spectra collected from one day were converted to absorbance spectra using this zap-bkg. Another method, referred to as the synthetic background method, was generated from this same original SB spectrum using IMACC software (Industrial Monitoring and Control Corp., Round Rock, TX). In this case, numerous points in the non-absorbing region of the SB spectrum were selected as base points, and a high- 

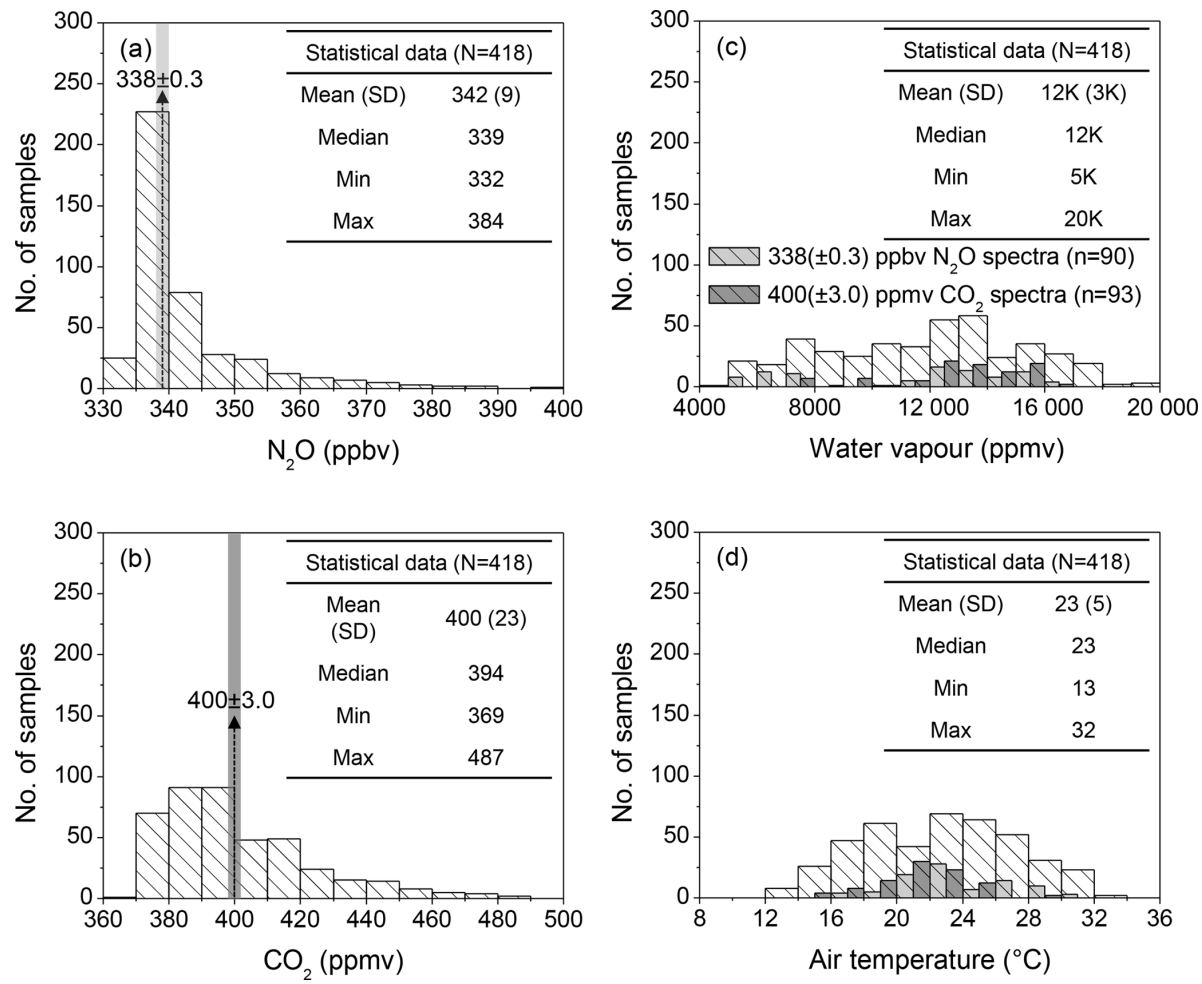

Figure 2. The 30 min averaged concentrations of (a) $\mathrm{N}_{2} \mathrm{O}$ and (b) $\mathrm{CO}_{2}$ were measured using $\mathrm{N}_{2} \mathrm{O}$ and $\mathrm{CO}_{2}$ analysers by sampling the air from S-OPS, and the $30 \mathrm{~min}$ averages of (c) water vapour content and (d) air temperature were also measured from the on-site weather station during 9-19 June 2014. The concentrations of $\mathrm{N}_{2} \mathrm{O}, \mathrm{CO}_{2}$, and water vapour shown in these figures were measured while the air was well-mixed $\left(U>1.5 \mathrm{~m} \mathrm{~s}^{-1}\right)$. The light grey bars mean the OP-FTIR spectra contained $338 \pm 0.3$ ppbv $\mathrm{N}_{2} \mathrm{O}$ and the dark grey bars mean the OP-FTIR spectra contained $400 \pm 3.0$ ppmv $\mathrm{CO}_{2}$. Both selected spectra $\left(\mathrm{N}_{2} \mathrm{O} 338 \mathrm{ppbv}, n=90 ; \mathrm{CO}_{2} 400\right.$ ppmv, $\left.n=93\right)$ covered the broad ranges of water vapour and air temperature and were used to assess the sensitivity of the OP-FTIR quantitative methods to dynamic ambient variables.

order fitting function was used to construct a background spectrum. An example in the $\mathrm{N}_{2} \mathrm{O} / \mathrm{CO}_{2}$ regions is illustrated in Fig. $3 \mathrm{~b}$ and labelled synthetic background (syn-bkg). Six points within $2050.0-2500.0 \mathrm{~cm}^{-1}$ were selected to fit the curvature of the SB spectrum using a polynomial function to create a syn-bkg SB spectrum (Fig. 3b). The mathematically manipulated SB spectra were used as background files to convert the sampled SB spectra into absorbance spectra (Fig. 3c and d). For the syn-bkg method, all data points were stored as one data file, and this file was applied to each sampled SB spectrum to create its syn-bkg. Since the selected points determined the curvature of the syn-bkg SB spectrum, it is critical to choose the data points that do not introduce any distortion (e.g. artificial dips and peaks) into the synbkg. In general, we avoided selecting data points within the absorption feature of interest (e.g. $2170.0-2224.0 \mathrm{~cm}^{-1}$ for $\mathrm{N}_{2} \mathrm{O}$ analysis), and the number of data points used to fit the curvature of the SB spectrum was considered adequate if it produced a smooth function (Russwurm and Childers, 1996). Adding too many data points may lead to artificial distortion in a syn-bkg. Because the syn-bkg is one of the recom- mended methods for spectral analysis (ASTM, 2013), it was used to assess the feasibility of the zap-bkg method.

\subsubsection{Gas quantifications: multivariate models and spectral window selections}

Based on the Beer-Lambert law, we used reference spectra to predict gas concentrations from field absorbance spectra. In this study, classical least squares (CLS) and partial least squares (PLS) regressions were used to calculate $\mathrm{N}_{2} \mathrm{O}$ and $\mathrm{CO}_{2}$ concentrations. The details of these two methods are described as follows.

- CLS prediction model. Each of the reference spectra used in the CLS model contained only one gas component (e.g. $\mathrm{N}_{2} \mathrm{O}, \mathrm{CO}_{2}$, or water vapour), and these reference spectra were generated from the high-resolution transmission molecular absorption (HITRAN) database (Rothman et al., 2005). The CLS model (AutoQuant Pro4.0) predicted gas concentrations from the field absorbance spectra converted using the zap-bkg method. In addition, CLS spectra were also calculated using the IMACC software to predict gas concentrations from 
(a) Single beam (SB) field spectrum

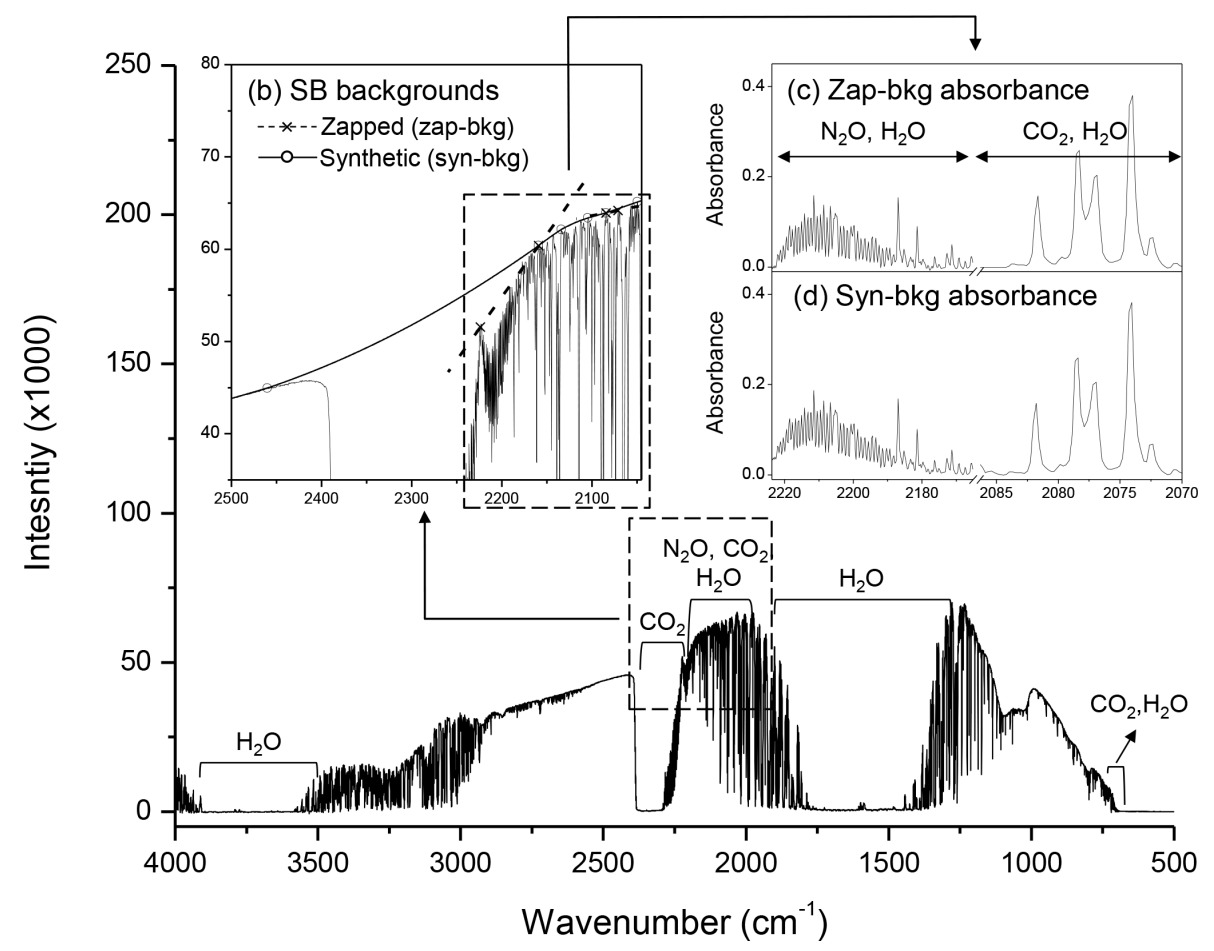

Figure 3. The illustrations of (a) a field single-beam (SB) OP-FTIR spectrum containing the regions of $\mathrm{N}_{2} \mathrm{O}, \mathrm{CO}_{2}$, and water vapour collected through an optical path length of $300 \mathrm{~m}$; (b) zapped and synthetic SB backgrounds (zap-bkg and syn-bkg) generated from this field SB spectrum and used to convert the sampled SB spectrum to (c) the absorbance spectra that allowed the calculation of $\mathrm{N}_{2} \mathrm{O} / \mathrm{CO}_{2}$ concentrations using the Beer-Lambert law.

the spectra converted by the syn-bkg method. The nonlinear function between the actual and predicted gas concentrations of the reference spectra was selected in the CLS model in both quantitative packages.

- PLS prediction model. Each of the reference spectra used in the PLS model consisted of multiple gas components (e.g. an $\mathrm{N}_{2} \mathrm{O}$ plus $\mathrm{H}_{2} \mathrm{O}$ mixing spectrum). Gas samples were delivered to a multi-pass gas cell (White cell) with an optical path length of $33 \mathrm{~m}$ (model MARS8L/40L, Gemini Scientific Instruments, CA). Spectra were collected by a laboratory-based FTIR spectrometer (Nexus 670, Thermo Electron Corporation, Madison, WI), which included a globar IR source, a $\mathrm{KBr}$ beam splitter, and a mercury cadmium telluride highD* (MCT-High D*) detector. The FTIR spectrometer was purged with dry air $\left(-20^{\circ} \mathrm{C}\right.$ dew point $)$ produced by a zero air generator (model $701 \mathrm{H}$, Teledyne, Thousand Oaks, CA). Certified $\mathrm{N}_{2} \mathrm{O}$ was diluted with ultrapure $\mathrm{N}_{2}$ gas using a diluter (series 4040, Environics Inc, Tolland, CT), and the water vapour content was controlled by a Nafion tube (Perma Pure, Lakewood, NJ) contained within a sealed container of saturated water vapour. Temperature and humidity were monitored using a humidity and temperature transmitter (model
HMT330, Vaisala Oyj, Helsinki, Finland). The $\mathrm{N}_{2} \mathrm{O}$ concentrations were diluted from $30 \mathrm{ppmv}$ to $0.30,0.40$, $0.50,0.60$, and $0.70 \mathrm{ppmv}$ and mixed with water vapour to a relative humidity of $20 \%, 40 \%, 60 \%$, and $80 \%$ at $303 \mathrm{~K}$. Spectra were acquired at $0.5 \mathrm{~cm}^{-1}$ resolution and averaged from 64 sample scans with triangular apodization. A total of 60 spectra of $\mathrm{N}_{2} \mathrm{O}$ plus $\mathrm{H}_{2} \mathrm{O}$ mixtures were used to build the PLS model using quantitative spectral-processing software (Thermo Fisher Scientific TQ Analyst version 8.0). In order to avoid overfitting the models, the optimum set of factors used in PLS models was determined by cross validation and justified by the prediction of residual error sum of squares (PRESS) function. The correlation between known and PLS-predicted concentrations was used to quantify $\mathrm{N}_{2} \mathrm{O}$ from the field absorbance spectrum converted by synbkg within given spectral windows.

- Spectral window selections. The window selection (Fig. 4) was critical because of interferences of water vapour. While a broader window contained more information of the gas of interest and potentially improved the spectral fit between the modelled and sampled spectra and the quantitative accuracy, it also included more features of water vapour and led to bi- 
ases in gas quantifications. On the other hand, a narrow window can minimize the interfering effect of the uninteresting gases but may reduce the spectral information of the targeted gas, which lead to biases in gas calculations (e.g. underestimation of gas quantification). The window used for $\mathrm{N}_{2} \mathrm{O}$ quantifications was 2130.0 to $2224.0 \mathrm{~cm}^{-1}$, which mainly includes the absorbance features of $\mathrm{N}_{2} \mathrm{O}$ (P branch) and water vapour, and other regions $\left(W_{\mathrm{N}} 1-4\right.$ shown in Fig. $\left.4 \mathrm{a}\right)$ were also selected for calculating $\mathrm{N}_{2} \mathrm{O}$ concentrations. For $\mathrm{CO}_{2}$, the spectral windows of $2070.0-2085.0$ and $722.0-800.0 \mathrm{~cm}^{-1}$ (not shown) contain features of $\mathrm{CO}_{2}$ and water vapour (Rothman et al., 2005). Multiple windows ( $W_{\mathrm{C}} 1-3$ shown in Fig. 4c) were selected to calculate $\mathrm{CO}_{2}$ concentrations and assess the effect of water vapour on gas predictions.

\subsection{The accuracy of the FTIR-calculated concentration and statistical analysis}

Bias, the relative error between the S-OPS and OP-FTIRmeasured $\mathrm{N}_{2} \mathrm{O} / \mathrm{CO}_{2}$, indicated the accuracy of the calculated $\mathrm{N}_{2} \mathrm{O}$ or $\mathrm{CO}_{2}$ concentrations using different spectral analyses (i.e. background types, multivariate models, and spectral windows) and can be calculated with Eq. (1):

$\operatorname{Bias}=\frac{\left(x_{i}-x_{t}\right)}{x_{t}} \times 100 \%$,

where $x_{i}$ is the $\mathrm{N}_{2} \mathrm{O}$ or $\mathrm{CO}_{2}$ concentration calculated from the OP-FTIR spectrum, and $x_{t}$ is the known $\mathrm{N}_{2} \mathrm{O}$ or $\mathrm{CO}_{2}$ concentration measured by the S-OPS. The calculated biases were statistically analysed by ANOVA procedures and the protected least significant difference (LSD) was used for multiple comparisons among population mean biases $(\alpha=$ 0.05) (SAS 9.3; SAS Institute Inc., 2012).

\section{Results and discussion}

\subsection{Quantitative methods (SB backgrounds, spectral windows, and multivariate models)}

Both SB background methods (zap- and syn-bkg) were used to convert the sampled SB spectra to absorbance spectra for gas quantifications. Different windows $\left(W_{\mathrm{N}} 1-4\right.$ for $\mathrm{N}_{2} \mathrm{O}$ and $W_{\mathrm{C}} \mathrm{l}-3$ for $\mathrm{CO}_{2}$ ) were used to calculate $\mathrm{N}_{2} \mathrm{O} / \mathrm{CO}_{2}$ concentrations from absorbance spectra using CLS and PLS models. A series of the OP-FTIR spectra acquired from broad ranges of humidity (i.e. 5000-20 $000 \mathrm{ppmv}$ water vapour) and temperature $\left(10-35^{\circ} \mathrm{C}\right)$ were used to calculate $\mathrm{N}_{2} \mathrm{O}$ and $\mathrm{CO}_{2}$ concentrations. Within these ranges, the mean bias (\%) indicated the accuracy of $\mathrm{N}_{2} \mathrm{O}$ or $\mathrm{CO}_{2}$ quantification, and the standard deviation (SD) referred to the sensitivity of quantitative methods to water vapour content and air temperature.

\subsection{Nitrous oxide (338 ppbv)}

Spectral windows experiencing less water vapour interference generally improved the accuracy of $\mathrm{N}_{2} \mathrm{O}$ quantification. In the CLS model, $\mathrm{N}_{2} \mathrm{O}$ concentrations calculated from the absorbance spectra converted by zap-bkg were underestimated by $10.7 \pm 2.3 \%$ using the broadest window $\left(W_{N} 1\right.$ : $2170.0-2223.7 \mathrm{~cm}^{-1}$ shown in Fig. 4a). This bias was reduced using $W_{\mathrm{N}} 2\left(2188.5-2223.7 \mathrm{~cm}^{-1}\right)$ (i.e. bias $=-9.1 \pm$ $2.5 \%$ shown in Fig. 5a). Likewise, $\mathrm{N}_{2} \mathrm{O}$ concentrations derived from the absorbance spectra converted by syn-bkg were underestimated by $8.2 \pm 2.6 \%$ using the $W_{\mathrm{N}} 1$. This bias was reduced using $W_{\mathrm{N}} 3\left(2215.8-2223.7+2188.5-2204.1 \mathrm{~cm}^{-1}\right)$ (i.e. bias $=-5.6 \pm 2.6 \%$ shown in Fig. 5b). Although interferences of water vapour can be mitigated by narrowing down spectral windows, the narrowest window $\left(W_{N} 4\right.$ : 2188.5-2204.1 $\mathrm{cm}^{-1}$ ) used in the CLS model resulted in greater biases than the $W_{\mathrm{N}} 3$ in both zap- and syn-bkg procedures (Fig. 5a and b). The narrowed window also lost $\mathrm{N}_{2} \mathrm{O}$ absorption features and presumably increased biases if the analytical window was over-confined. The P-branch feature of $\mathrm{N}_{2} \mathrm{O}$ extended from 2130.0 to $2223.7 \mathrm{~cm}^{-1}$, and this region was also used to calculate $\mathrm{N}_{2} \mathrm{O}$ concentrations. In the CLS model, the window of $2130.0-2223.7 \mathrm{~cm}^{-1}$ showed the minimum mean bias of $-0.4 \%$ of the calculated $\mathrm{N}_{2} \mathrm{O}$ concentrations using syn-bkg (data not shown); however, this window was sensitive to interfering water vapour and led to the highest variability in $\mathrm{N}_{2} \mathrm{O}$ estimations (i.e. $-0.4 \pm 5.3 \%$ ).

As previously mentioned, it was important to generate a reasonable background for the spectral analysis. In the CLS model, the bias of $\mathrm{N}_{2} \mathrm{O}$ quantification using the synbkg was significantly lower than the zap-bkg based on the same spectral window $\left(W_{N} 1-3 ; p<0.05\right)$ (Fig. 5a and b). The syn-bkg method coupled with the integrated window of $2215.8-2223.7$ and $2188.7-2204.1 \mathrm{~cm}^{-1}\left(W_{\mathrm{N}} 3\right)$ was considered the optimal combination for $\mathrm{N}_{2} \mathrm{O}$ quantifications using CLS models (i.e. lowest bias $=-5.6 \pm 2.6 \%$ in CLS shown in Fig. 5b). This optimal combination was also used in the PLS model to predict $\mathrm{N}_{2} \mathrm{O}$ concentrations. The mean bias of the calculated $\mathrm{N}_{2} \mathrm{O}$ was reduced from $-5.6 \%$ (CLS model) to $-0.3 \%$ (PLS model) (Fig. 5b and c). As compared with the CLS model, the PLS model significantly improved the accuracy of $\mathrm{N}_{2} \mathrm{O}$ quantification $(p<0.05)$ presumably because the PLS algorithm can extract useful latent factors from the $\mathrm{N}_{2} \mathrm{O}$ plus $\mathrm{H}_{2} \mathrm{O}$ mixing spectra (e.g. the contribution of water vapour to $\mathrm{N}_{2} \mathrm{O}$ ).

\subsection{Carbon dioxide (400 ppmv)}

For $\mathrm{CO}_{2}$ estimations, three spectral windows were used in the $2070.0-2084.0 \mathrm{~cm}^{-1}$ range (Fig. 4c). The accuracy of $\mathrm{CO}_{2}$ quantification was also improved by narrowing down spectral windows (Fig. 6). In the CLS model, $\mathrm{CO}_{2}$ concentrations calculated from the absorbance spectra converted by zap-bkg were underestimated by $6.4 \pm 4.1 \%$ using the 

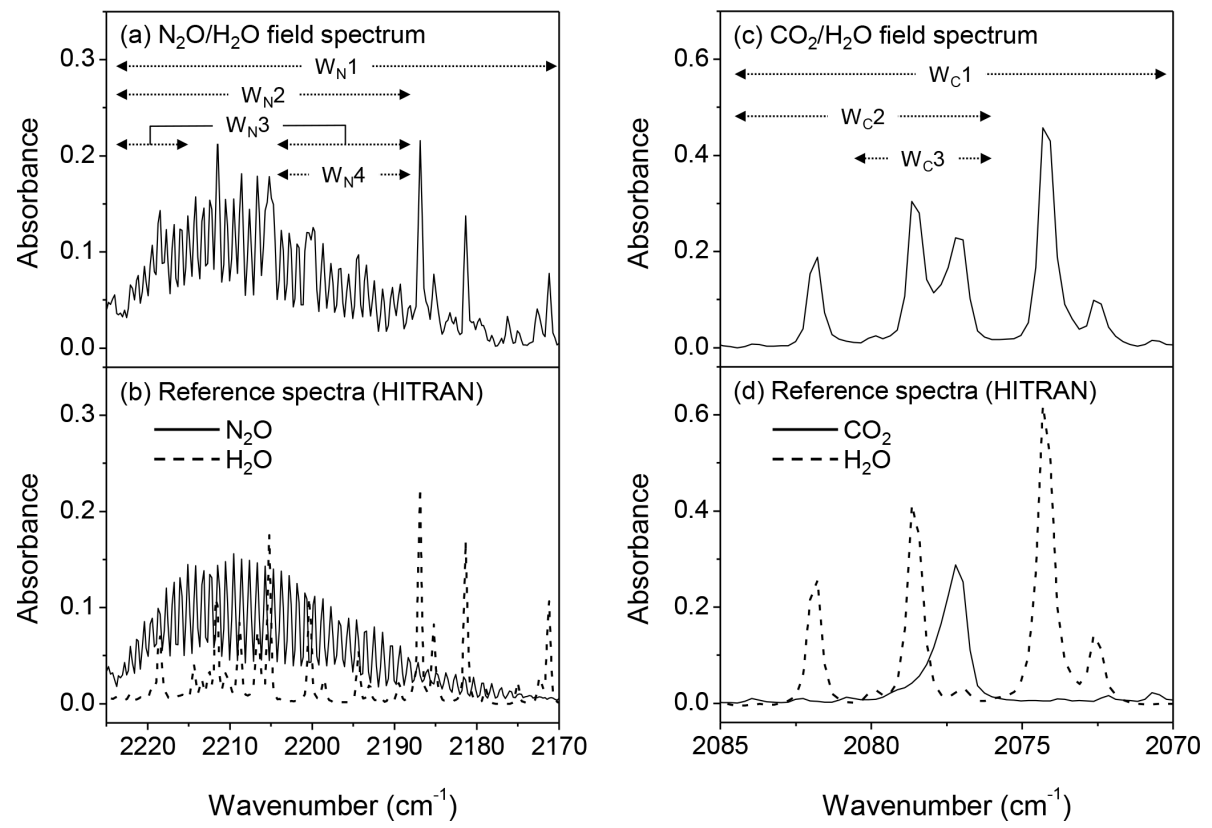

Figure 4. Field and HITRAN reference absorbance spectra: (a) field spectrum containing the features of $\mathrm{N}_{2} \mathrm{O}$ and water vapour, (b) reference spectra of $\mathrm{N}_{2} \mathrm{O}$ and water vapour at $2170.0-2224.0 \mathrm{~cm}^{-1}$, (c) field spectrum containing the features of $\mathrm{CO}_{2}$ and water vapour, and (d) reference spectra of $\mathrm{CO}_{2}$ and water vapour at $2070.0-2084.0 \mathrm{~cm}^{-1} . W_{\mathrm{N}}(1-4)$ and $W_{\mathrm{C}}(1-3)$ denote the spectral windows used to calculate $\mathrm{N}_{2} \mathrm{O}$ and $\mathrm{CO}_{2}$ concentrations from field spectra.

broadest window $\left(W_{\mathrm{C}} 1: 2070.0-2084.0 \mathrm{~cm}^{-1}\right)$. This bias was reduced by the narrowed window of $W_{\mathrm{C}} 2(2075.5-$ $2084.0 \mathrm{~cm}^{-1}$ ) (i.e. bias $=-0.1 \pm 4.2 \%$ shown in Fig. 6a). The bias of the calculated $\mathrm{CO}_{2}$ concentrations was $-4.7 \pm$ $2.5 \%$ using $W_{\mathrm{C}} 1$ coupled with syn-bkg and reduced to $-0.3 \pm 2.4 \%$ using $W_{C} 2$ (Fig. $6 b$ ). The most confined window $\left(W_{\mathrm{C}} 3: 2075.5-2080.5 \mathrm{~cm}^{-1}\right)$ resulted in greater biases than $W_{\mathrm{C}} 2$, and particularly in conjunction with zap-bkg (i.e. bias $=3.2 \pm 3.4 \%$ shown in Fig. 6a). Thus, the range from 2075.5 to $2084.0 \mathrm{~cm}^{-1}\left(W_{\mathrm{C}} 2\right)$ was the optimal window for $\mathrm{CO}_{2}$ quantification using the CLS model (Fig. 4c).

The zap-bkg led to a greater underestimate in $\mathrm{N}_{2} \mathrm{O}$ (bias $=-10 \pm 2.3 \%$ shown in Fig. 5a) than $\mathrm{CO}_{2}$ calculations (bias $=-0.1 \pm 4.2 \%$ shown in Fig. 6a) based on the optimal window ( $W_{\mathrm{N}} 3$ and $\left.W_{\mathrm{C}} 2\right)$ used in CLS models. Since the absorbance feature of $\mathrm{CO}_{2}$ at $2076.9 \mathrm{~cm}^{-1}$ (the band centre) was less complicated than the $\mathrm{P}$ branch of $\mathrm{N}_{2} \mathrm{O}$ from 2170.0 to $2223.7 \mathrm{~cm}^{-1}$, the $\mathrm{CO}_{2}$ absorbance converted by zap-bkg was similar to syn-bkg (Fig. 3c and d). Therefore, the calculated bias showed that there was no significant difference between zap- and syn-bkg methods for $\mathrm{CO}_{2}$ concentration calculations using the $W_{\mathrm{C}} 2$ (Fig. 6). Zap-bkg, however, led to the higher variability in the calculated $\mathrm{CO}_{2}$, indicating that simply removing the $\mathrm{CO}_{2}$ feature by the linear function potentially resulted in biases for $\mathrm{CO}_{2}$ quantification.

The other potential region for $\mathrm{CO}_{2}$ quantification was within 722.0-800.0 $\mathrm{cm}^{-1}$ (the $\mathrm{R}$ branch of $\mathrm{CO}_{2} \nu_{2}$ band shown in Fig. 3a). Different windows were examined for cal- culating $\mathrm{CO}_{2}$ concentrations using the CLS model in this region, and the $\mathrm{CO}_{2}$ concentrations were underestimated by $40 \%-70 \%$ no matter which window was used in conjunction with zap-bkg. The mean bias was minimized (bias $=-9.0 \pm$ $2.9 \%$ ) by using two windows of 723.0-727.7 and 732.0$738.5 \mathrm{~cm}^{-1}$ in conjunction with syn-bkg (data not shown). As compared with the results from the $2070.0-2084.0 \mathrm{~cm}^{-1}$ range (Fig. 4c), the $722.0-800.0 \mathrm{~cm}^{-1}$ window resulted in a significant underestimation of $\mathrm{CO}_{2}$ concentration because (1) more water vapour features interfered with the $\mathrm{R}$ branch of $\mathrm{CO}_{2}$ features in the $722.0-800.0 \mathrm{~cm}^{-1}$ range than $\mathrm{CO}_{2}$ in the $2070.0-2084.0 \mathrm{~cm}^{-1}$ range and (2) it was difficult to simulate the appropriate background at the low wavenumber region in the SB spectrum.

\subsection{Diurnal $\mathrm{N}_{2} \mathrm{O}$ and $\mathrm{CO}_{2}$ estimations}

The quantitative approach leading to the minimum bias in $\mathrm{N}_{2} \mathrm{O}$ estimations was to use syn-bkg with the $W_{\mathrm{N}} 3$ window in the PLS model (Fig. 5c). For $\mathrm{CO}_{2}$, only the CLS model was used for calculating concentrations because of missing $\mathrm{CO}_{2} / \mathrm{H}_{2} \mathrm{O}$ mixing spectra for PLS models. The approach leading to the minimum bias in $\mathrm{CO}_{2}$ estimations in this study was to use syn-bkg with the $W_{\mathrm{C}} 2$ window in the CLS model (Fig. 6b). These procedures were used to estimate $\mathrm{N}_{2} \mathrm{O}$ and $\mathrm{CO}_{2}$ concentrations from the OP-FTIR spectra collected from 9 to 19 June 2014 (Fig. 7). The diurnal fluctuations in $\mathrm{N}_{2} \mathrm{O}$ and $\mathrm{CO}_{2}$ concentrations corresponded to diurnal changes of wind speed and air temperature. The 


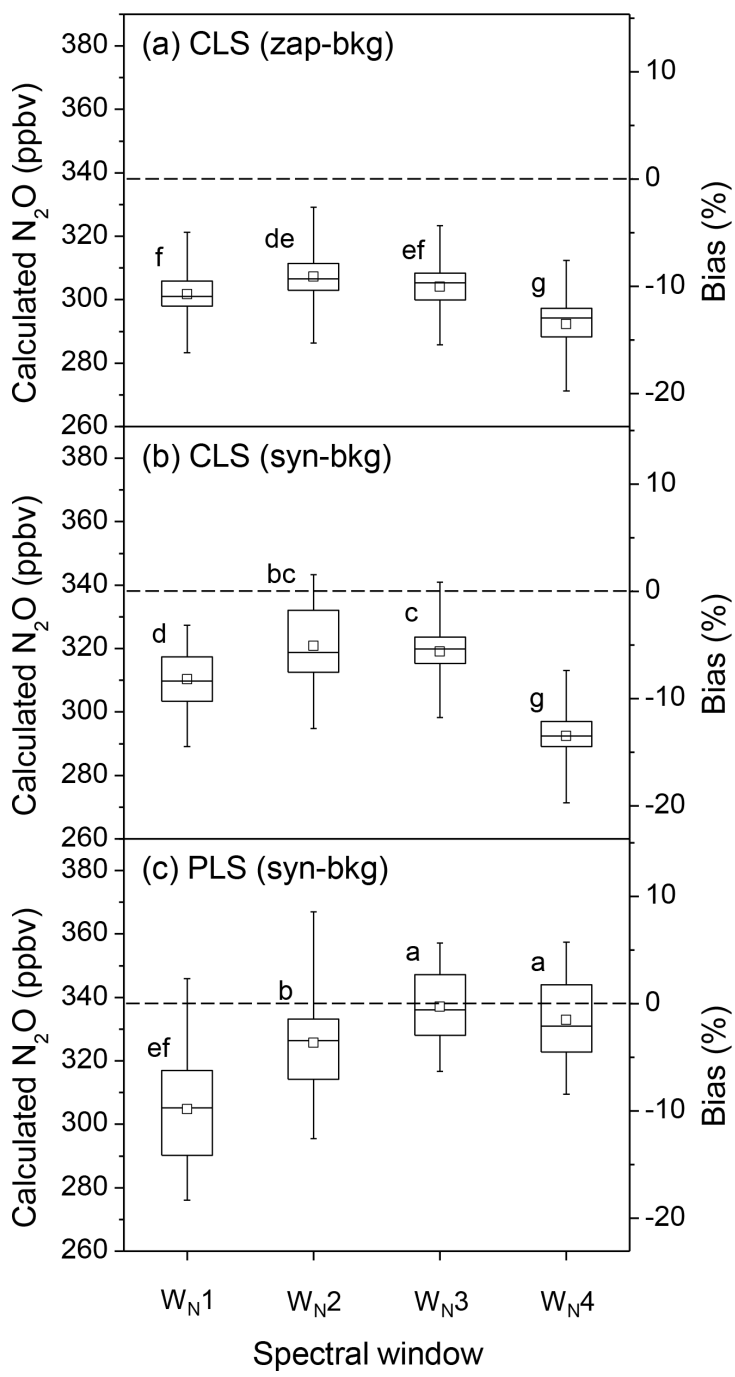

Figure 5. The box plots of the calculated $\mathrm{N}_{2} \mathrm{O}$ concentrations and the corresponding biases from a series of OP-FTIR spectra $(n=$ 90) that contain $338 \pm 0.3 \mathrm{ppbv} \mathrm{N}_{2} \mathrm{O}$ with varying humidity and air temperature using different $\mathrm{SB}$ background-processing methods (zap-bkg and syn-bkg) and four spectral windows $\left(W_{N} 1-4\right)$ in the CLS and PLS models: (a) zap-bkg + CLS model, (b) synbkg + CLS model, and (c) syn-bkg + PLS model. The plot displays the mean $(\square)$, median (-), interquartile ranges (box), and extreme values (whiskers). Different letters indicate significant differences $(p<0.05)$ among the means calculated by different quantitative methods by the least significant difference (LSD).

higher $\mathrm{N}_{2} \mathrm{O} / \mathrm{CO}_{2}$ concentrations were usually measured during the night because of $\mathrm{N}_{2} \mathrm{O} / \mathrm{CO}_{2}$ accumulations. The accumulation of $\mathrm{N}_{2} \mathrm{O} / \mathrm{CO}_{2}$ occurred near the ground when turbulent mixing was low, resulting from decreasing buoyancy from the ground surface (i.e. a stable atmosphere). The greater density of air parcels due to decreasing temperature also led to gas accumulation. The diurnal variation in $\mathrm{CO}_{2}$ was greater than $\mathrm{N}_{2} \mathrm{O}$ (Fig. 7b), and we hypothesized it was due to multiple sources of $\mathrm{CO}_{2}$. While $\mathrm{N}_{2} \mathrm{O}$ was mostly pro-

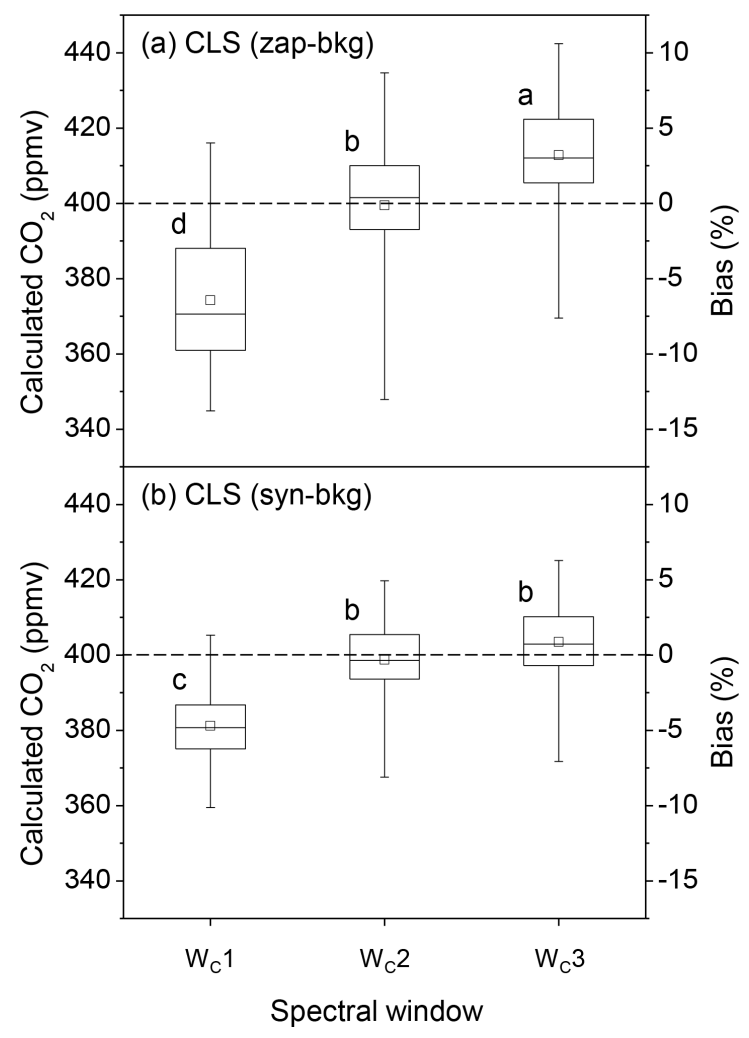

Figure 6. The box plots of the calculated $\mathrm{CO}_{2}$ concentrations and the corresponding biases from a series of OP-FTIR spectra $(n=93)$ that contain $400 \pm 3.0$ ppmv $\mathrm{CO}_{2}$ with varying humidity and air temperature using different $\mathrm{SB}$ background-processing methods (zap-bkg and syn-bkg) and three spectral windows ( $W_{\mathrm{C}} 1-$ 3 ) in the CLS model: (a) zap-bkg and (b) syn-bkg. The plot displays the mean $(\square)$, median (-), interquartile ranges (box), and extreme values (whiskers). Different letters indicate significant differences $(p<0.05)$ among the means calculated by different quantitative methods by the least significant difference (LSD).

duced from soils via microbial nitrification and denitrification, $\mathrm{CO}_{2}$ was emitted via soil respiration (including microbes and corn root) as well as respiration from grass and corn leaves.

Mixing of the surface layer of air tended to result in greater homogeneity along the optical path. Under low wind speed, the presumably poorly mixed air increased the variability of the path-averaged $\mathrm{N}_{2} \mathrm{O} / \mathrm{CO}_{2}$ concentrations along the optical path, resulting in the difference between the $50 \mathrm{~m} \mathrm{~S}$-OPS and the $150 \mathrm{~m}$ OP-FTIR. The calculated biases of $\mathrm{N}_{2} \mathrm{O}$ and $\mathrm{CO}_{2}$ were $1.3 \pm 2.6 \%(n=363)$ and $-0.7 \pm 5.8 \%(n=327)$, respectively, while the mean wind velocity ranged from 0.1 to $8.4 \mathrm{~m} \mathrm{~s}^{-1}$ (Fig. 7). The variability of the calculated biases of $\mathrm{N}_{2} \mathrm{O}$ and $\mathrm{CO}_{2}$ was reduced when the data that were collected in low wind speeds $\left(<1.7 \mathrm{~m} \mathrm{~s}^{-1}\right)$ were excluded, i.e. $\operatorname{bias}_{\mathrm{N}_{2} \mathrm{O}}=1.4 \pm 2.3 \%(n=298)$ and $\operatorname{bias}_{\mathrm{CO}_{2}}=-1.0 \pm 2.8 \%$ $(n=272)$. 


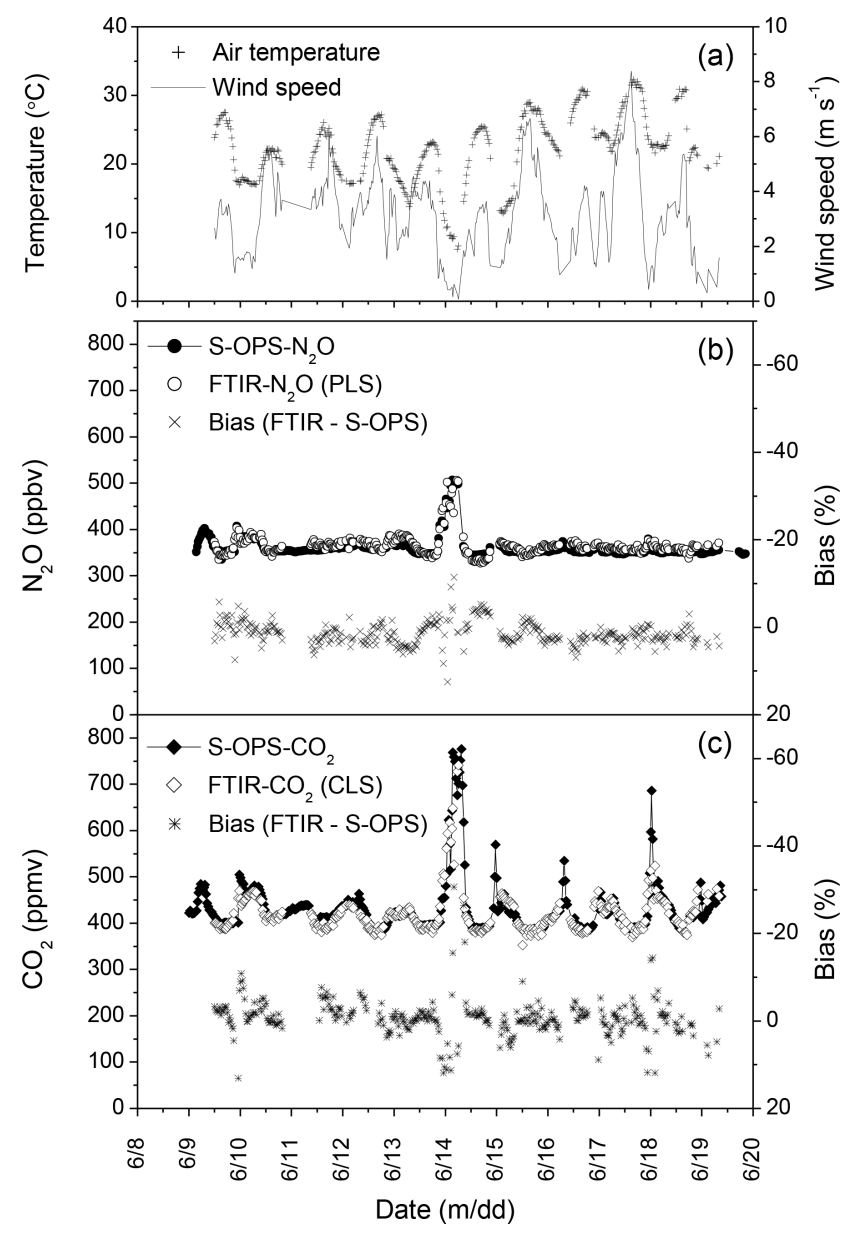

Figure 7. Measurements of air temperature, wind speed, $\mathrm{N}_{2} \mathrm{O}$, and $\mathrm{CO}_{2}$ concentrations from 9 to 19 June 2014. The 30 min averages of (a) air temperature and wind speed; (b) $\mathrm{N}_{2} \mathrm{O}$ concentrations measured from $\mathrm{S}$-OPS using the DFG $\mathrm{N}_{2} \mathrm{O}$ analyser and calculated from OP-FTIR using the method of (syn-bkg $+W_{\mathrm{N}} 3+$ PLS), as well as the corresponding biases; and (c) $\mathrm{CO}_{2}$ concentrations measured from S-OPS using LI-840 $\mathrm{CO}_{2}$ analyser and calculated from OPFTIR using the method of (syn-bkg $+W_{\mathrm{C}} 2+$ CLS), as well as the corresponding biases.

\section{Conclusions}

We have developed and evaluated different methods for quantifying concentrations of nitrous oxide and carbon dioxide using open-path FTIR based on combinations of singlebeam backgrounds (zap-bkg and syn-bkg), analytical windows $\left(W_{\mathrm{N}} 1-4\right.$ and $\left.W_{\mathrm{C}} 1-3\right)$, and chemometric multivariate calibration models (CLS and PLS). It is challenging to generate the P-branch $\mathrm{N}_{2} \mathrm{O}$ absorbance within 2170.0 $2223.7 \mathrm{~cm}^{-1}$ to predict $\mathrm{N}_{2} \mathrm{O}$ accurately but feasible to generate absorbance within $2075.5-2084.0 \mathrm{~cm}^{-1}$ for $\mathrm{CO}_{2}$ prediction using the zap-bkg method. The principle for selecting spectral windows is that using the region with less water vapour features while over-confining the analytical region may lead to biases in gas predictions. The CLS model, the most common approach used for gas retrievals in OP-FTIR commercial packages, underestimates $\mathrm{N}_{2} \mathrm{O}$ concentrations but predicts $\mathrm{CO}_{2}$ accurately within an absolute humidity range of 5000-20000 ppmv and a temperature range of $10-35^{\circ} \mathrm{C}$. In this study, the method resulting in the minimum bias for $\mathrm{N}_{2} \mathrm{O}$ quantification is to use the combination of syn-bkg, a two-band window (2188.7 $\left.2204.1+2215.8-2223.7 \mathrm{~cm}^{-1}\right)$, and the PLS model $\left(\mathrm{N}_{2} \mathrm{O}\right.$ bias $=1.4 \pm 2.3 \%$ ). The method leading to the minimum bias in $\mathrm{CO}_{2}$ quantification is to use the combination of syn-bkg, the $2075.5-2084.0 \mathrm{~cm}^{-1}$ window, and the CLS model $\left(\mathrm{CO}_{2}\right.$ bias $=-1.0 \pm 2.8 \%$ ). We describe comprehensive methods of $\mathrm{N}_{2} \mathrm{O}$ and $\mathrm{CO}_{2}$ analyses for the increasing number of OPFTIR users who are interested in greenhouse gas emissions from agricultural fields.

Data availability. All measurement data used in this study are archived at the Purdue University Research Repository (PURR) under $r$ https://doi.org/10.4231/06W5-J904 (Lin et al., 2019).

Supplement. The supplement related to this article is available online at: https://doi.org/10.5194/amt-12-3403-2019-supplement.

Author contributions. CHL, CTJ, RHG, and AJH designed the laband field-FTIR measurements experiment and spectral analyses. CHL and RHG conducted the FTIR experiment. CHL conducted the data analysis and prepared the manuscript with contributions from CTJ, RHG, and AJH.

Competing interests. The authors declare that they have no conflict of interest.

Acknowledgements. The authors would like to thank Tony Vyn and Terry West for crop and field management, Austin Pearson for data collection and analysis, and the Purdue University Climate Change Research Center for the additional travel grant support.

Financial support. This research has been supported by the United States Department of Agriculture National Institute for Food and Agriculture, USDA NIFA (grant no. 13-68002-20421), and the Indiana Corn Marketing Council (grant no. 12076053).

Review statement. This paper was edited by Frank Hase and reviewed by three anonymous referees. 


\section{References}

ASTM International: ASTM E1865-97(2013) Standard Guide for Open-Path Fourier Transform Infrared (OP/FT-IR) Monitoring of Gases and Vapors in Air, West Conshohocken, PA, https://doi.org/10.1520/E1865-97R13, 2013a.

ASTM International: ASTM E1982-98(2013) Standard Practice for Open-Path Fourier Transform Infrared (OP/FT-IR) Monitoring of Gases and Vapors in Air, West Conshohocken, PA, https://doi.org/10.1520/E1982-98R13, 2013b.

Bacsik, Z., Komlosi, V., Ollar, T., and Mink, J.: Comparison of open path and extractive long-path FTIR techniques in detection of air pollutants, Appl. Spectrosc. Rev., 41, 77-97, https://doi.org/10.1080/05704920500385494, 2006.

Bai, M., Suter, H., Lam, S. K., Sun, J. L., and Chen, D. L.: Use of open-path FTIR and inverse dispersion technique to quantify gaseous nitrogen loss from an intensive vegetable production site, Atmos. Environ., 94, 687-691, https://doi.org/10.1016/j.atmosenv.2014.06.013, 2014.

Bai, M., Suter, H., Lam, S. K., Davies, R., Flesch, T. K., and Chen, D. L.: Gaseous emissions from an intensive vegetable farm measured with slant-path FTIR technique, Agric. For. Meteorol., 258, 50-55, https://doi.org/10.1016/j.agrformet.2018.03.001, 2018.

Baldocchi, D. D.: Assessing the eddy covariance technique for evaluating carbon dioxide exchange rates of ecosystems: past, present and future, Glob. Change Biol., 9, 479-492, https://doi.org/10.1046/j.1365-2486.2003.00629.x, 2003.

Barrancos, J., Briz, S., Nolasco, D., Melian, G., Padilla, G., Padron, E., Fernandez, I., Perez, N., and Hernandez, P. A.: A new method for estimating greenhouse gases and ammonia emissions from livestock buildings, Atmos. Environ., 74, 10-17, https://doi.org/10.1016/j.atmosenv.2013.03.021, 2013.

Bjorneberg, D. L., Leytem, A. B., Westermann, D. T., Griffiths, P. R., Shao, L., and Pollard, M. J.: Measurement of atmospheric ammonia, methane, and nitrous oxide at a concentrated dairy production facility in southern Idaho using open-path FTIR spectrometry, Trans. ASABE, 52, 1749-1756, 2009.

Bremner, J. M., Breitenbeck, G. A., and Blackmer, A. M.: Effect of nitrapyrin on emission of nitrous oxide from soil fertilized with anhydrous ammonia, Geophys. Res. Lett., 8, 353-356, https://doi.org/10.1029/GL008i004p00353, 1981.

Briz, S., de Castro, A. J., Díez, S., López, F., and Schäfer, K.: Remote sensing by open-path FTIR spectroscopy. Comparison of different analysis techniques applied to ozone and carbon monoxide detection, J. Quant. Spectrosc. Ra., 103, 314-330, https://doi.org/10.1016/j.jqsrt.2006.02.058, 2007.

Childers, J. W., Russwurm, G. M., and Thompson, E. L.: Quality assurance considerations in a long-term FTIR monitoring program, Proc. SPIE, 2365, 389-395, https://doi.org/10.1117/12.210812, 1995.

Childers, J. W., Thompson, E. L., Harris, D. B., Kirchgessner, D. A., Clayton, M., Natschke, D. F., and Phillips, W. J.: Multipollutant concentration measurements around a concentrated swine production facility using open-path FTIR spectrometry, Atmos. Environ., 35, 1923-1936, https://doi.org/10.1016/s13522310(00)00545-8, 2001a.

Childers, J. W., Thompson, E. L., Harris, D. B., Kirchgessner, D. A., Clayton, M., Natschke, D. F., and Phillips, W. J.: Application of standardized quality control procedures to openpath Fourier transform infrared data collected at a concentrated swine production facility, Environ. Sci. Technol., 35, 1859-1866, https://doi.org/10.1021/es001744f, 2001b.

Cole, C. V., Duxbury, J., Freney, J., Heinemeyer, O., Minami, K., Mosier, A., Paustian, K., Rosenberg, N., Sampson, N., Sauerbeck, D., and Zhao, Q.: Global estimates of potential mitigation of greenhouse gas emissions by agriculture, Nutr. Cycl. Agroecosyst., 49, 221-228, https://doi.org/10.1023/a:1009731711346, 1997.

Denmead, O. and Reicosky, D.: Tillage-induced gas fluxes: comparison of meteorological and large chamber techniques, Proc. ISTRO, 16, 357-363, 2003.

Denmead, O. T.: Approaches to measuring fluxes of methane and nitrous oxide between landscapes and the atmosphere, Plant Soil, 309, 5-24, https://doi.org/10.1007/s11104-008-9599-z, 2008.

Eichner, M. J.: Nitrous oxide emissions from fertilized soils: Summary of available data, J. Environ. Qual., 19, 272280, https://doi.org/10.2134/jeq1990.00472425001900020013x, 1990.

Flesch, T. K., Wilson, J. D., Harper, L. A., Crenna, B. P., and Sharpe, R. R.: Deducing ground-to-air emissions from observed trace gas concentrations: A field trial, J. Appl. Meteorol., 43, 487-502, https://doi.org/10.1175/15200450(2004)043<0487:dgefot>2.0.co;2, 2004.

Flesch, T. K., Baron, V. S., Wilson, J. D., Griffith, D. W. T., Basarab, J. A., and Carlson, P. J.: Agricultural gas emissions during the spring thaw: Applying a new measurement technique, Agric. For. Meteorol., 221, 111-121, https://doi.org/10.1016/j.agrformet.2016.02.010, 2016.

Frey, M., Hase, F., Blumenstock, T., Groß, J., Kiel, M., Mengistu Tsidu, G., Schäfer, K., Sha, M. K., and Orphal, J.: Calibration and instrumental line shape characterization of a set of portable FTIR spectrometers for detecting greenhouse gas emissions, Atmos. Meas. Tech., 8, 3047-3057, https://doi.org/10.5194/amt-8 3047-2015, 2015.

Gosz, J. R., Dahm, C. N., and Risser, P. G.: Long-path FTIR measurement of atmospheric trace gas concentrations, Ecology, 69, 1326-1330, https://doi.org/10.2307/1941630, 1988.

Griffiths, P. R. and de Haseth, J. A.: Fourier transform infrared spectrometry, John Wiley \& Sons, Hoboken, 2007.

Heber, A. J., Ni, J. Q., Lim, T. T., Tao, P. C., Schmidt, A. M., Koziel, J. A., Beasley, D. B., Hoff, S. J., Nicolai, R. E., Jacobson, L. D., and Zhang, Y. H.: Quality assured measurements of animal building emissions: Gas concentrations, J. Air Waste Manage. Assoc., 56, 1472-1483, https://doi.org/10.1080/10473289.2006.10465680, 2006.

Herget, W. F. and Brasher, J. D.: Remote Fourier transform infrared air pollution studies, Opt. Eng., 19, 194508-194508, https://doi.org/10.1117/12.7972551, 1980.

Horrocks, L. A., Oppenheimer, C., Burton, M. R., Duffell, H. J., Davies, N. M., Martin, N. A., and Bell, W.: Openpath Fourier transform infrared spectroscopy of $\mathrm{SO}_{2}$ : An empirical error budget analysis, with implications for volcano monitoring, J. Geophys. Res.-Atmos., 106, 27647-27659, https://doi.org/10.1029/2001jd000343, 2001.

IPCC: Intergovernmental Panel on Climate Change, Fourth Assessment Report-Working I Report: The physical science basis, Cambridge Univ. Press, Cambridge, 2007.

Kelliher, F. M., Reisinger, A. R., Martin, R. J., Harvey, M. J., Price, S. J., and Sherlock, R. R.: Measuring nitrous oxide emission 
rate from grazed pasture using Fourier-transform infrared spectroscopy in the nocturnal boundary layer, Agric. For. Meteorol., 111, 29-38, https://doi.org/10.1016/s0168-1923(02)000072, 2002.

Laville, P., Jambert, C., Cellier, P., and Delmas, R.: Nitrous oxide fluxes from a fertilised maize crop using micrometeorological and chamber methods, Agric. For. Meteorol., 96, 19-38, https://doi.org/10.1016/s0168-1923(99)00054-4, 1999.

Lin, C., Liou, N., and Sun, E.: Applications of open-path Fourier transform infrared for identification of volatile organic compound pollution sources and characterization of source emission behaviors, J. Air Waste Manage. Assoc., 58, 821-828, https://doi.org/10.3155/1047-3289.58.6.821, 2008.

Lin, C., Johnston, C., Grant, R. H., and Heber, A.: Application of Open Path Fourier Transform Infrared Spectroscopy (OP-FTIR) to Measure Greenhouse Gas Concentrations from Agricultural Fields, Purdue University Research Repository, https://doi.org/10.4231/06W5-J904, 2019.

Loh, Z., Chen, D., Bai, M., Naylor, T., Griffith, D., Hill, J., Denmead, T., McGinn, S., and Edis, R.: Measurement of greenhouse gas emissions from Australian feedlot beef production using open-path spectroscopy and atmospheric dispersion modelling, Aust. J. Exp. Agric., 48, 244-247, https://doi.org/10.1071/ea07244, 2008.

Mosier, A., Wassmann, R., Verchot, L., King, J., and Palm, C.: Methane and nitrogen oxide fluxes in tropical agricultural soils: Sources, sinks and mechanisms, Environ. Dev. Sustain., 6, 11-49, https://doi.org/10.1023/B:ENVI.0000003627.43162.ae, 2004.

Naylor, T. A., Wiedemann, S. G., Phillips, F. A., Warren, B., McGahan, E. J., and Murphy, C. M.: Emissions of nitrous oxide, ammonia and methane from Australian layer-hen manure storage with a mitigation strategy applied, Anim. Prod. Sci., 56, 1367-1375, https://doi.org/10.1071/an15584, 2016.

Ni, K., Koster, J. R., Seidel, A., and Pacholski, A.: Field measurement of ammonia emissions after nitrogen fertilization-A comparison between micrometeorological and chamber methods, Eur. J. Agron., 71, 115-122, https://doi.org/10.1016/j.eja.2015.09.004, 2015.

Omonode, R. A., Halvorson, A. D., Gagnon, B., and Vyn, T. J.: Achieving lower nitrogen balance and higher nitrogen recovery efficiency reduces nitrous oxide emissions in North America's maize cropping systems, Front. Plant Sci., 8, 1080, https://doi.org/10.3389/fpls.2017.01080, 2017.

Paustian, K., Andren, O., Janzen, H. H., Lal, R., Smith, P., Tian, G., Tiessen, H., Van Noordwijk, M., and Woomer, P. L.: Agricultural soils as a sink to mitigate $\mathrm{CO}_{2}$ emissions, Soil Use Manage., 13, 230-244, https://doi.org/10.1111/j.14752743.1997.tb00594.x, 1997.

Poulsen, T. G., Furman, A., and Liberzon, D.: Effects of wind speed and wind gustiness on subsurface gas transport, Vadose Zone J., 16, https://doi.org/10.2136/vzj2017.04.0079, 2017.

Pourbakhtiar, A., Poulsen, T. G., Wilkinson, S., and Bridge, J. W.: Effect of wind turbulence on gas transport in porous media: experimental method and preliminary results, Eur. J. Soil Sci., 68, 48-56, https://doi.org/10.1111/ejss.12403, 2017.

Reiche, N., Westerkamp, T., Lau, S., Borsdorf, H., Dietrich, P., and Schütze, C.: Comparative study to evaluate three groundbased optical remote sensing techniques under field conditions by a gas tracer experiment, Environ. Earth Sci., 72, 1435-1441, https://doi.org/10.1007/s12665-014-3312-8, 2014.

Rochette, P. and Eriksen-Hamel, N. S.: Chamber measurements of soil nitrous oxide flux: are absolute values reliable?, Soil Sci. Soc. Am. J., 72, 331-342, https://doi.org/10.2136/sssaj2007.0215, 2008.

Rothman, L. S., Jacquemart, D., Barbe, A., Benner, D. C., Birk, M., Brown, L. R., Carleer, M. R., Chackerian, C., Chance, K., Coudert, L. H., Dana, V., Devi, V. M., Flaud, J. M., Gamache, R. R., Goldman, A., Hartmann, J. M., Jucks, K. W., Maki, A. G., Mandin, J. Y., Massie, S. T., Orphal, J., Perrin, A., Rinsland, C. P., Smith, M. A. H., Tennyson, J., Tolchenov, R. N., Toth, R. A., Vander Auwera, J., Varanasi, P., and Wagner, G.: The HITRAN 2004 molecular spectroscopic database, J. Quant. Spectrosc. Ra., 96, 139-204, https://doi.org/10.1016/j.jqsrt.2004.10.008, 2005.

Rowlings, D. W., Grace, P. R., Kiese, R., and Weier, K. L.: Environmental factors controlling temporal and spatial variability in the soil-atmosphere exchange of $\mathrm{CO}_{2}, \mathrm{CH}_{4}$ and $\mathrm{N}_{2} \mathrm{O}$ from an Australian subtropical rainforest, Glob. Change Biol., 18, 726-738, https://doi.org/10.1111/j.1365-2486.2011.02563.x, 2012.

Russwurm, G. M. and Childers, J. W.: FT-IR open-path monitoring guidance document, ManTech Environmental Technology, Inc., Research Triangle Park, NC (United States), 1996.

Russwurm, G. M., Kagann, R. H., Simpson, O. A., McClenny, W. A., and Herget, W. F.: Long-path FTIR measurements of volatile organic-compounds in an industrialsetting, J. Air Waste Manage. Assoc., 41, 1062-1066, https://doi.org/10.1080/10473289.1991.10466900, 1991.

Ryden, J. C. and Lund, L. J.: Nitrous oxide evolution from irrigated land ${ }^{1}$, J. Environ. Qual., 9, 387-393, https://doi.org/10.2134/jeq1980.00472425000900030012x, 1980.

SAS Institute: The SAS system for Windows, Version 9.3, SAS Inst., Cary, NC, 2012.

Schelde, K., Cellier, P., Bertolini, T., Dalgaard, T., Weidinger, T., Theobald, M. R., and Olesen, J. E.: Spatial and temporal variability of nitrous oxide emissions in a mixed farming landscape of Denmark, Biogeosciences, 9, 2989-3002, https://doi.org/10.5194/bg-9-2989-2012, 2012.

Schmid, H. P.: Source areas for scalars and scalar fluxes, Bound.Lay. Meteor., 67, 293-318, https://doi.org/10.1007/bf00713146, 1994.

Shao, L., Pollard, M. J., Griffiths, P. R., Westermann, D. T., and Bjorneberg, D. L.: Rejection criteria for openpath Fourier transform infrared spectrometry during continuous atmospheric monitoring, Vib. Spectrosc., 43, 78-85, https://doi.org/10.1016/j.vibspec.2006.06.016, 2007.

Smith, P.: Carbon sequestration in croplands: the potential in Europe and the global context, Eur. J. Agron., 20, 229-236, https://doi.org/10.1016/j.eja.2003.08.002, 2004.

Smith, P., Martino, D., Cai, Z., Gwary, D., Janzen, H., Kumar, P., McCarl, B., Ogle, S., O’Mara, F., Rice, C., Scholes, B., and Sirotenko, O.: Agriculture, in: Mitigation, edited by: Metz, B. et al., Contribution of Working Group III to the fourth assessment report of the Intergovernmental Panel on Climate Change, Cambridge Univ. Press, Cambridge, UK, 2007.

Smith, P., Martino, D., Cai, Z., Gwary, D., Janzen, H., Kumar, P., McCarl, B., Ogle, S., O'Mara, F., Rice, C., Scholes, B., Sirotenko, O., Howden, M., McAllister, T., Pan, 
G., Romanenkov, V., Schneider, U., Towprayoon, S., Wattenbach, M., and Smith, J.: Greenhouse gas mitigation in agriculture, Philos. Trans. R. Soc. B-Biol. Sci., 363, 789-813, https://doi.org/10.1098/rstb.2007.2184, 2008.

Smith, T. E. L., Wooster, M. J., Tattaris, M., and Griffith, D. W. T.: Absolute accuracy and sensitivity analysis of OP-FTIR retrievals of $\mathrm{CO}_{2}, \mathrm{CH}_{4}$ and $\mathrm{CO}$ over concentrations representative of "clean air" and "polluted plumes", Atmos. Meas. Tech., 4, 97116, https://doi.org/10.5194/amt-4-97-2011, 2011.
US-EPA: Global Anthropogenic Emissions of Non- $\mathrm{CO}_{2}$ Greenhouse Gases: 1990-2020, United States Environmental Protection Agency, EPA 430-R-06-003, Washington, D.C., available at: https://www.epa.gov/sites/production/files/2016-05/documents/ globalanthroemissionsreport.pdf (last access: 1 October 2018), 2006.

West, T. O. and McBride, A. C.: The contribution of agricultural lime to carbon dioxide emissions in the United States: dissolution, transport, and net emissions, Agric. Ecosyst. Environ., 108, 145-154, https://doi.org/10.1016/j.agee.2005.01.002, 2005. 